\title{
A high concentration of fasting plasma non-esterified fatty acids is a risk factor for the development of NIDDM
}

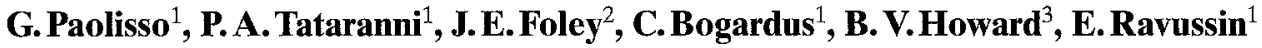 \\ ${ }^{1}$ Clinical Diabetes and Nutrition Section, National Institute of Diabetes and Digestive and Kidney Diseases, National Institutes \\ of Health, Phoenix, Arizona, USA \\ ${ }^{2}$ Department of Diabetes, Sandoz Research Institute, East Hannover, New Jersey, USA \\ ${ }^{3}$ Medlantic Research Institute, Washington, District of Columbia, USA
}

Summary To assess the role of fasting plasma nonesterified fatty acids (NEFA) in the development of non-insulin-dependent diabetes mellitus (NIDDM), data were analysed from annual examinations of 190 non-diabetic Pima Indians. Glucose tolerance was measured by a 75 -g oral glucose tolerance test, insulin action by a euglycaemic hyperinsulinaemic $\left(40 \mathrm{mU} \cdot \mathrm{m}^{-2} \cdot \mathrm{min}^{-1}\right)$ clamp and in vitro lipolysis using isolated abdominal fat cells. After a mean follow-up period of $4.0 \pm 2.4$ years (mean $\pm \mathrm{SD}$ ), 47 subjects developed NIDDM. Risk factors for NIDDM were estimated by proportional-hazards analysis and risk ratios (RR) with $95 \%$ confidence intervals $(95 \% \mathrm{CI})$ calculated at the 90 th and 10 th percentile of the predictor variables. A large average fat-cell volume was predictive of $\operatorname{NIDDM}(\mathrm{RR}=2.4$; $95 \% \mathrm{CI}=1.2-4.8$ ) independent of age, sex, percent body fat and body fat distribution. A high fasting plasma NEFA concentration was also a risk factor for NIDDM $(\mathrm{RR}=2.3 ; 95 \% \mathrm{CI}=1.1-4.7)$ independent of sex, percent body fat, waist/thigh ratio, insulin-mediated glucose uptake and fasting triglyceride concentration. We conclude that large fat cells and the resulting increased plasma NEFA concentrations are risk factors for the development of NIDDM. [Diabetiologia (1995) 38: 1213-1217]

Key words Non-esterified fatty acids, non-insulin-dependent diabetes mellitus, obesity, insulin action, "in vitro" lipolysis.
An increased production rate of non-esterified fatty acids (NEFA) from adipose tissue could be responsible for insulin resistance, the main risk factor for the development of non-insulin dependent diabetes mellitus NIDDM [1]. Thirty years ago, Randle et al. [2] proposed that the glucose/fatty acid cycle might cause the alteration in insulin action observed in NIDDM patients. They documented that elevated NEFA concentrations result in increased fat oxidation with a secondary decrease in the activity of the enzymes pyruvate dehydrogenase and phosphofructokinase [3]. The resulting accumulation of glucose 6-phosphate in turn inhibits hexokinase, glucose up-

Received: 29 December 1994 and in revised form: 27 March 1995

Corresponding author: E. Ravussin Ph.D., CDNS-NIDDKNIH, 4212 N. 16th Street, Rm.541-A, Phoenix, AZ 85016, USA

Abbreviations: NEFA, Non-esterified fatty acids; NIDDM, non-insulin-dependent diabetes mellitus; CI, confidence interval; RR, risk ratio. take and glucose oxidation. An acute increase in plasma NEFA concentrations induced by lipid/heparin infusion causes a decrease in insulin-mediated glucose disposal [4-6] while an acute decrease in NEFA concentrations by antilipolytic agents is accompanied by an increase in insulin-mediated glucose oxidation [7-8]. Enhanced NEFA availability increases lipid oxidation which in turn inhibits both glucose oxidation and non-oxidative glucose metabolism $[9,10]$. The inhibitory effect of NEFA on non-oxidative glucose disposal seems to result from the inhibition of glycogen synthase $[9,10]$.

Surprisingly, despite the abundance of information on the physiological role of plasma NEFA on carbohydrate metabolism, no prospective study has been designed to address whether high plasma NEFA concentration predicts the development of NIDDM independently of insulin resistance. We have, therefore, tested whether large fat cells and high rates of in vitro fat-cell lipolysis are associated with high plasma fasting NEFA concentrations and whether these three factors are predictive of NIDDM. 
Table 1. Characteristics of 190 non-diabetic Pima Indians

\begin{tabular}{lcc}
\hline & Males & Females \\
\hline$n$ & 93 & 97 \\
Body weight $(\mathrm{kg})$ & $98.8 \pm 27.0(50.3-190.3)$ & $93.5 \pm 22.6(47.8-202.0)$ \\
Height $(\mathrm{cm})$ & $170.3 \pm 5.2(159.2-182.0)$ & $159.1 \pm 5.0(147.5-170.0)$ \\
Body fat (\%) & $33 \pm 10(10-54)$ & $46 \pm 7(28-60)$ \\
Waist/thigh ratio & $1.65 \pm 0.18(1.28-2.08)$ & $1.61 \pm 0.15(1.34-2.11)$ \\
Glucose disposal $\mathrm{mg} \cdot \mathrm{kg} \mathrm{EMBS}$ & $3.3 \pm 0.8(2.1-5.8)$ \\
Acute insulin response $(\mathrm{mU} / 1)^{\mathrm{a}}$ & $3.6 \pm 1.3(2.1-8.6)$ & $354 \pm 327(-48-1837)$
\end{tabular}

Data are mean \pm SD (range)

EMBS, Estimated metabolic body size = fat-free body mass

${ }^{\text {a }} n=49$ for males and 54 for females

$+14 \mathrm{~kg}[15]$

\section{Subjects and methods}

Subjects. From 1982 through 1992, 200 non-diabetic Pima Indians were enrolled in prospective studies of the development of NIDDM [1]. Only 190 subjects (97 women and 93 men; age $26 \pm 6$ years) in whom plasma NEFA concentrations were measured are included in this analysis (Table 1). Among these subjects, 156 were included in our previous longitudinal analysis of precursors of NIDDM [1]. The subjects were asked to return each year for testing that included a 75 -g oral glucose tolerance test [11] and a euglycaemic hyperinsulinaemic glucose clamp. Glucose tolerance was normal in 133 volunteers and impaired in the remaining 57 subjects. The study protocol was approved by the ethics committees of the National Institute of Diabetes and Digestive and Kidney Disease (NIDDK) and the Indian Health Service, and by the Gila River Indian Community. Subjects gave written informed consent.

In vivo studies. All subjects were admitted to the metabolic ward of the Clinical Diabetes and Nutrition Section of the NIDDK for 8 to 15 days, during which they were fed a weight-maintaining diet. Body fat mass and fat-free mass were determined by underwater weighing $[12,13]$. The waist circumference of each subject was measured at the umbilicus (lying) and the thigh circumference at the gluteal fold (standing). The ratio of the two circumferences was used as an index of body fat distribution.

A euglycaemic hyperinsulinaemic (insulin infusion rate: $40 \mathrm{mU} \cdot \mathrm{m}^{-2} \cdot \mathrm{min}^{-1}$ ) glucose clamp was performed to measure insulin action, as previously described [14]. Before the clamp, substrate oxidation was determined by indirect calorimetry [4]. Glucose uptake and oxidation rates were normalized to estimated metabolic body sizes, calculated as fat-free body mass plus $14 \mathrm{~kg}$ [15]. Three fasting blood samples were drawn before the clamp study to measure plasma NEFA concentrations, while another blood sample was drawn on a different day for plasma triglyceride determination.

In a subset of 103 subjects, acute plasma insulin response to intravenous glucose ( $25 \mathrm{~g}$ injected over $3.6 \mathrm{~min}$ ) was also determined. Blood samples were collected at 3,4 and 5 min following the injection, and the response was calculated as the incremental area under the curve from the third to the fifth min divided by two.

In vitro studies. After an overnight fast, subcutaneous abdominal adipose tissue cells were obtained as previously reported [16]. Isolated adipocytes were prepared by the collagenase technique according to Kashiwagi et al. [17]. Adipose cell size was determined by sizing osmium-fixed cells on a Coulter electronic counter with $400-\mu \mathrm{m}$ aperture equipped with logarithmic range expander channelyser (Coulter Electronics, Irvine, Calif., USA). Lipolysis was measured by incubating isolated ad- ipocytes in $0.5 \mathrm{ml} 5 \%$ albumin-Hepes buffer at $37^{\circ} \mathrm{C}$ for $2 \mathrm{~h}$ with continuous shaking at $40 \mathrm{cycles} / \mathrm{min}$. The buffer contained either no isoproterenol or $25 \mathrm{nmol} / 1$ isoproterenol in the presence of $0,12.5,25,50,100,200$ and $8000 \mathrm{pmol} / 1$ insulin. The incubation was terminated by the flotation method [18]. Under these conditions, glycerol release was linear for at least $3 \mathrm{~h}$ [16]. The concentration of insulin resulting in half-maximum suppression of $25 \mathrm{nmol} / 1$ isoproterenol-stimulated lipolysis $\left(\mathrm{ED}_{50}\right.$ antilipolysis) was calculated as previously reported [16].

Analytical methods. Plasma glucose concentration was measured by the glucose oxidase method using a Beckman Glucose Analyzer (Fullerton, Calif., USA). Plasma insulin concentration was determined by the modification of Herbert et al. [19] of the radioimmunoassay of Yalow and Berson [20]. NEFA were measured according to Miles et al. [21] and plasma triglyceride by the method of Bucolo and David [22].

Statistical analyses. Statistical analyses were performed using computer programs from the SAS Institute (Cary, N.C., USA). Plasma insulin and triglyceride concentrations were $\log$ transformed to approximate normal distributions. Correlations are Pearson product-moment correlations. To estimate the impact of variables on the development of NIDDM independent of the duration of follow-up, proportional-hazards analyses were performed [23]. For a factor positively associated with NIDDM, the risk ratio estimates the relative hazard for a hypothetical subject at the 90th percentile divided by the hazard for a subject at the 10 th percentile after adjustments for different covariates. Ninety-five percent confidence limits are presented for each risk ratio.

\section{Results}

Subject characteristics are reported in Table 1. After a mean follow-up of $4.0 \pm 2.4$ years 47 subjects (12 males and 35 females) developed NIDDM according to the World Health Organization criteria [11]. These 47 subjects were of similar age, but showed higher fasting and 2-h plasma glucose levels than the remaining 143 subjects $(97 \pm 9$ vs $93 \pm 8$ $\mathrm{mmol} / 1, p<0.007$ and $146 \pm 28$ vs $122 \pm 28 \mathrm{mmol} / \mathrm{l}$, $p<0.0001$, respectively). The average follow-up period for the remaining 143 subjects was $4.2 \pm$ 2.4 years.

Large mean fat-cell size was predictive of NIDDM ( $R R=4.3, C I=2.2-8.2)$, and remained predictive after adjusting for age, sex, percent body fat 
Table 2. In vitro fat-cell characteristics and development of NIDDM

\begin{tabular}{|c|c|c|c|c|}
\hline \multirow[b]{2}{*}{ Average volume cell size ( $\mu \mathrm{g}$ lipid/cell) ${ }^{\mathrm{a}}$} & \multicolumn{2}{|c|}{$\begin{array}{l}\text { Values at } 10 \text { th } \\
\text { and } 90 \text { th percentile }\end{array}$} & \multirow{2}{*}{$\begin{array}{l}\text { Risk ratio } \\
2.4\end{array}$} & \multirow{2}{*}{$\begin{array}{l}\text { Confidence } \\
\text { interval }\end{array}$} \\
\hline & 0.53 & 1.05 & & \\
\hline Basal lipolysis $\left(\mathrm{fmol} \cdot \operatorname{cell}^{-1} \cdot \mathrm{s}^{-1}\right)^{b}$ & 0.04 & 0.22 & 1.3 & $0.6-2.7$ \\
\hline Isoproterenol-stimulated lipolysis per cell $\left(\mathrm{fmol} \cdot \operatorname{cell}^{-1} \cdot \mathrm{s}^{-1}\right)^{\mathrm{b}}$ & 0.45 & 1.06 & 2.0 & $0.8-4.8$ \\
\hline Isoproterenol stimulated lipolysis per cell surface area $\left(\mathrm{fmol} \cdot \mu \mathrm{m}^{-2 b} \cdot \mathrm{s}^{-1}\right)^{\mathrm{b}}$ & 11.7 & 21.8 & 1.5 & $0.8-2.9$ \\
\hline $\mathrm{ED}_{50}$ for insulin suppression of isoproterenol-stimulated lipolysis $(\mathrm{pmol} / \mathrm{l})^{\mathrm{b}}$ & 8 & 58 & 1.2 & $0.6-2.2$ \\
\hline
\end{tabular}

* Risk ratios (the risk of the 90 th vs 10 th percentile of the predictive variable) and $95 \%$ confidence intervals were calculated by proportional hazard analysis. a Adjusted for age, sex, percent body fat and waist/thigh circumference.

${ }^{\mathrm{b}}$ Adjusted for age, sex, fat cell size and waist/thigh circumference

Table 3. NEFA and development of NIDDM

\begin{tabular}{|c|c|c|}
\hline NEFA effect independent of: & Risk ratio & $\begin{array}{l}\text { Confidence } \\
\text { interval }\end{array}$ \\
\hline Age, sex, percent body fat, waist/thigh & 2.2 & $1.1-4.2$ \\
\hline Sex, percent body fat, $M$ & 2.1 & $1.1-4.2$ \\
\hline Sex, percent body fat, $M$, acute insulin response ${ }^{a}$ & 2.0 & $0.7-5.3$ \\
\hline Sex, percent body fat, waist/thigh circumference, $M$, fasting plasma triglyceride concentration & 2.3 & $1.1-4.8$ \\
\hline
\end{tabular}

Risk ratios and $95 \%$ confidence intervals shown when comparing 90th $(485 \mu \mathrm{mol} / \mathrm{l})$ and 10 th percentile $(248 \mu \mathrm{mol} / \mathrm{l})$ of plasma NEFA concentrations

Statistical significance of the analytical models was similar when only the 133 subjects with normal glucose tolerance test were included

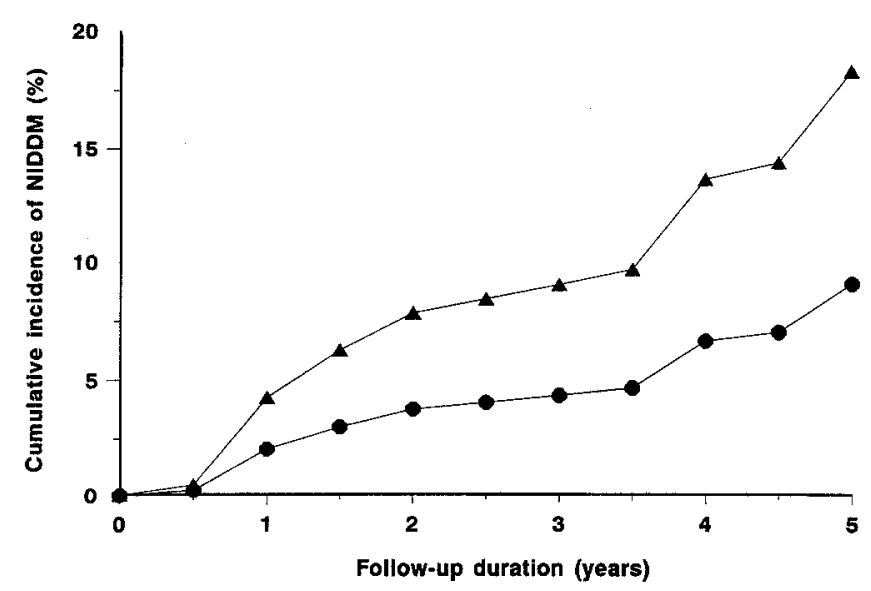

Fig. 1. Predicted cumulative incidence (\%) of developing NIDDM for subjects at the 90 th $(485 \mu \mathrm{mol} / \mathrm{l})(\mathbf{A})$ and 10 th $(248 \mu \mathrm{mol} / \mathrm{l})(\bullet)$ percentile of NEFA distribution. The predictive effect of NEFA is adjusted for differences in sex, percent body fat and insulin-mediated glucose uptake

and body fat distribution ( $\mathrm{RR}=2.4, \mathrm{CI}=1.2-4.8$ ) (Table 2). Basal ( $\mathrm{RR}=2.3, \mathrm{CI}=1.3-4.3)$ and isoproterenol-stimulated $(\mathrm{RR}=2.6, \mathrm{CI}=1.5-4.8)$ lipolysis were both predictive of NIDDM when values were expressed per cell, but not after adjusting for fatcell size (Table 2). Similarly, the $\mathrm{ED}_{50}$ for the inhibition of lipolysis by insulin was predictive of NIDDM, but not after adjustment for average volume cell size.
${ }^{a}$ Only 103 subjects with acute insulin response measurements were available for analysis

M, Insulin-mediated glucose uptake
Mean fat-cell size correlated with basal lipolysis $(r=0.29 p<0.0002)$, percent body fat $(r=0.36$ $p<0.0002)$, fat mass $(r=0.28 p<0.001)$ and insulinmediated glucose disposal $(r=-0.38 p<0.0002)$. Plasma NEFA concentration correlated with fat-cell size $(r=0.24, p<0.001)$, basal lipolysis $(r=0.29$, $p<0.0002)$, basal lipid oxidation $(r=0.40$, $p<0.0001)$ and insulin-mediated glucose disposal $(r=-0.22, p<0.002)$. Fasting plasma NEFA concentration also correlated with 2 -h plasma glucose concentration $(r=0.22, p<0.002)$, but not with fasting plasma glucose or triglyceride.

High plasma NEFA concentration was predictive of NIDDM (RR $=3.5, \mathrm{CI}=2.0-6.1)$ even after adjusting for sex, percent body fat and insulin-mediated glucose uptake ( $\mathrm{RR}=2.1, \mathrm{CI}=1.1-4.2$ ) (Fig. 1), as well as after adjusting for body fat distribution and fasting plasma triglyceride concentration $(\mathrm{RR}=2.3, \mathrm{CI}=1.1-4.7)$ (Table 3$)$. When fat-cell size or acute insulin response were added to the model including sex, percent body fat and insulin-mediated glucose uptake, high plasma NEFA concentrations were no longer predictive of NIDDM (values available for acute insulin response in only 103 subjects; Table 3). All the above predictive relationships remained similar when the 57 subjects with impaired glucose tolerance were excluded.

Plasma triglyceride concentration $(\mathrm{RR}=1.5$, $\mathrm{CI}=0.7-3.4)$ and basal lipid oxidation $(\mathrm{RR}=1.0$, 
$\mathrm{CI}=0.5-2.1)$ were not predictive of NIDDM independent of age, sex, percent body fat and body fat distribution.

\section{Discussion}

Our study provides evidence that large fat cells and high fasting plasma NEFA concentration are predictive of the development of NIDDM.

The relationship between average fat-cell size and NIDDM is not surprising since the volume of adipocytes is strongly related to obesity, a major risk factor for the development of NIDDM [1]. It is likely that larger fat cells have higher rates of lipolysis, leading to increased plasma NEFA concentrations. This hypothesis is supported by our previous data showing that the size of the fat depot rather than the basal rate of lipolysis per se determines NEFA availability [24]. In the present study, such a mechanism is also suggested by the positive correlation between average fat-cell size, basal lipolysis and fasting plasma NEFA concentration.

The inhibitory role of NEFA on glucose disposal via an increase in lipid oxidation was first proposed by Randle et al. [2]. Subsequent clinical studies have shown that infusion of triglyceride emulsions (Intralipid) causes a decrease in both oxidative $[8,10]$ and non-oxidative $[5,6,10]$ glucose metabolism in man. When non-diabetic obese patients were compared to lean control subjects, glucose ingestion resulted in higher plasma glucose and insulin concentrations, probably due to impaired insulin action related to higher NEFA availability [25]. As recently reviewed by Felber et al. [10], increased lipid oxidation seems to inhibit glucose oxidation immediately, but to inhibit non-oxidative glucose metabolism after a delay. In this regard, it has been proposed that increased NEFA concentrations retard the rate of glycogen breakdown and inhibit glycogen synthase enzyme $[9,10,26]$. Evidence for this metabolic cascade was recently obtained in normal healthy subjects, during a euglycaemic hyperinsulinaemic glucose clamp with simultaneous triglyceride emulsion infusions $[27,28]$. These authors observed a correlation between the increase in lipid oxidation and the decrease in muscle glycogen concentration [27]. Kelley et al. [29] provided further evidence for this mechanism by showing that increased plasma NEFA concentration resulted in a decrease in insulin-mediated glucose uptake, leg respiratory quotient, and muscle glycogen storage [29]. All these metabolic effects were also accompanied by a decline in pyruvate dehydrogenase and glycogen synthase activity.

The glucose-fatty acid cycle cannot entirely explain the effect of NEFA on the development of NIDDM since, in our study: a) fasting plasma NEFA concentrations predict NIDDM independently of insulin-mediated glucose uptake; b) basal lipid oxidation is not a significant predictor of NIDDM; and c) the predictive value of fasting NEFA concentrations on the development of NIDDM disappears when acute insulin response is added to the statistical model. Taken together these observations suggest that factors other than the glucose/fatty acid cycle could explain the effect of NEFA on the development of NIDDM.

The observation that the predictive value of plasma NEFA on NIDDM was not significant after adjusting for acute insulin response, suggests that NEFA may increase the risk of NIDDM by inhibiting insulin secretion. This hypothesis is supported by recent data showing that NEFA may inhibit in vitro insulin release $[30,31]$ but not by some older studies $[32,33]$. In the study by Opara et al. [30] a 20-min exposure of islet cells to $5 \mathrm{mmol} / \mathrm{l}$ fatty acids resulted in enhancement or decrease of glucose-stimulated insulin secretions for $\mathrm{C} 16: \mathrm{O}$ or C18:2 fatty acids, respectively whereas Zhou and Grill [31] showed that long-term exposure to increased NEFA concentration inhibited glucose-induced insulin secretion [31]. An alternative explanation is that the impaired insulin release results in increased lipolysis and thus in elevated NEFA plasma levels. Similar findings have recently been reported by Lee et al. [34] who made a strong case for the role of high plasma NEFA levels in the pathogenesis of NIDDM in obese Zucker diabetic fatty rats and described the inhibitory effect of NEFA on beta-cell response to glucose. Also, circulating NEFA levels can affect liver metabolism. It has been shown that NEFA inhibit insulin receptor binding and tyrosine kinase activity in isolated hepatocytes [35] and provide energy for gluconeogenesis thus increasing hepatic glucose output $[36,37]$. However, since increased hepatic glucose production is not predictive of the development of NIDDM [1], the impact of NEFA on liver metabolism is unlikely to play an important role in the aetiology of NIDDM:

In conclusion, our results demonstrate that increased fasting plasma NEFA concentration is a significant independent risk factor for NIDDM. Further studies are needed to better understand all the possible effects of plasma NEFA on pathways of glucose metabolism, since the increased risk of NIDDM associated with higher plasma NEFA concentrations does not appear to be solely mediated through insulin action on glucose disposal.

Acknowledgements. We are indebted to Drs. P.H.Bennett, W.C. Knowler, and D.M. Mott who contributed substantially to the initial planning and design of this study; to all the physicians and staff members of the NIDDK in Phoenix and Sacaton who participated in data collection and to the residents and leaders of the Gila River Indian Community whose support is greatly appreciated. 


\section{References}

1. Lillioja S, Mott D, Spraul M et al. (1993) Insulin resistance as precursor of non-insulin dependent diabetes mellitus. Prospective studies of Pima Indians. N Engl J Med 329: 1988-1992

2. Randle PJ, Hales CN, Garland PB, Newsholme EA (1963) The glucose fatty-acid cycle. Its role in insulin insensitivity and the metabolic disturbances of diabetes mellitus. Lancet I: 785-789

3. Ashour D, Honsford RG (1983) Effect of free acids and ketones on the activity of pyruvate dehydrogenase in skeletal muscle mitochondria. Biochem J 214: 725-736

4. Lillioja S, Bogardus C, Mott D, Kennedy LA, Knowler WC, Howard BV (1985) Relationship between insulin mediated glucose disposal and lipid metabolism in man. J Clin Invest 75: 1106-1115

5. Ferrannini E, Barrett EJ, Bevilacqua S, De Fronzo RA (1983) Effect of fatty acids on glucose production and utilization in man. J Clin Invest 72: 1737-1747

6. Bonadonna RC, Zych K, Boni C, Ferrannini E, De Fronzo RA (1989) Time dependence of the interaction between lipid and glucose in humans. Am J Physiol 257: E 49-E 56

7. Balasse EO, Neef MA (1973) Influence of nicotinic acid on the rates of turnover and oxidation of plasma glucose in man. Metabolism 22: 1193-1204

8. Gomez F, Jéquier E, Chabot V, Buber V, Felber JP (1972) Carbohydrate and lipid oxidation in normal human subjects: its influence on glucose tolerance and insulin response to glucose metabolism. Metabolism 21: 381-391

9. Ebeling P, Koivisto VA (1994) Non-esterified fatty acids regulate lipid and glucose oxidation and glycogen synthesis in healthy man. Diabetologia 37: 202-209

10. Felber JP, Haesler E, Jéquier E (1993) Metabolic origin of insulin resistance in obesity with and without type 2 (noninsulin-dependent) diabetes mellitus. Diabetologia 36 : $1221-1229$

11. Diabetes Mellitus (1985) Report of a WHO study group. World Health Organization pp 9-17

12. Goldman RF, Bushkirk ER (1961) Body volume measurement by underwater weighing: description of a method. In: Brozek J, Herschel A (eds) Techniques for measuring body composition: proceedings of a conference. Quartermaster Research and Engineers Center, Natick, Mass. January 22-23, 1959 Washington D.C. National Research Council, pp 78-89

13. Siri WE (1961) Body composition from fluid spaces and density: analysis of methods. In: Brozek J, Herschel A (eds) Techniques for measuring body composition: proceedings of a conference: Quartermaster Research and Engineers Center, Natick, Mass. January 22-23, 1959 Washington D. C. National Research Council. pp 223-244

14. Lillioja S, Mott D, Howard BV, Bennet PH et al. (1988) Impaired glucose tolerance as a disorder of insulin action: longitudinal and cross-sectional studies in Pima Indians. $\mathrm{N}$ Engl J Med 318: 1217-1225

15. Lillioja S, Bogardus C (1988) Obesity and insulin resistance: lessons learned from Pima Indians. Diabetes Metab Rev 4: $517-540$

16. Foley J, Thuillez P, Lillioja S, Zawazki J, Bogardus C (1986) Insulin sensitivity in adipocytes from subjects with varying degree of glucose tolerance. Am J Physiol 251: E306-E310

17. Kashiwagi A, Verso MA, Andrews JA, Vasquez B, Reaven GM, Foley J (1983) In vitro insulin resistance of human adipocytes isolated from subjects with non-insulin dependent diabetes mellitus. J Clin Invest 72: 1246-1254
18. Gliemann J (1967) Assay of insulin-like activity by the isolated fat method. 1. Factors influencing the response to crystalline insulin. Diabetologia 3: 382-388

19. Herbert V, Lan K, Gottlieb CW, Bleicher SI (1965) Coated charcoal immunoassay of insulin. J Clin Endocrinol Metab 25: $1375-1384$

20. Yalow RS, Berson SA (1960) Immunoassay of endogenous plasma insulin in man. J Clin Invest 39: 1157-1167

21. Miles J, Glassoch R, Aiken J, Gerich J, Haymond A (1983) A microfluorimetric method for the determination of free fatty acids. J Lipid Res 24: 95-99

22. Bucolo G, David H (1973) Quantitative determination of serum triglycerides by the use of enzymes. Clin Chem 19: 476-482

23. Cox DR (1972) Regression model and life-tables. J Royal Statistic Soc 34: 187-220

24. Lillioja S, Foley J, Bogardus C, Mott D, Howard BV (1986) Free fatty acid metabolism and obesity in man: in vivo and in vitro comparisons. Metabolism 35: 505-514

25. Golay A, Felber JP, Jéquier E, De Fronzo RA, Ferrannini E (1988) Metabolic basis of obesity and non-insulin dependent diabetes mellitus. Diabetes Metab Rev 4: 727-747

26. Kida Y, Esposito-Del Puente A, Bogardus C, Mott D (1990) Insulin resistance is associated with reduced fasting and insulin-stimulated glycogen synthase phosphatase activity in human skeletal muscle. J Clin Invest 85: 476-481

27. Munger R, Temler E, Jallut D, Haesler E, Felber JP (1993) Correlations of glycogen synthase and phosphorylase activities with glycogen concentration in human muscle biopsies. Evidence for a double feed-back mechanism regulating glycogen synthesis and breakdown. Metabolism 42:36-43

28. Boden G, Chen X, Ruiz J, White JV, Rossetti L (1994) Mechanisms of fatty acid-induced inhibition of glucose uptake. J Clin Invest 93: 2438-2446

29. Kelley DE, Mokan M, Simoneau JA, Mandarino L (1993) Interaction between glucose and free fatty acid metabolism in human skeletal muscle. J Clin Invest 92: 91-98

30. Opara EC, Garfinkel M, Hubbard VS, Burch WM, Akwari OE (1994) Effect of fatty acids on insulin release: role of chain length and degree of unsaturation. Am J Physiol 266: E635-E639

31. Zhou YP, Grill VE (1994) Long-term exposure of rat pancreatic islets to fatty acids inhibits glucose-induced insulin secretion and biosynthesis through a glucose fatty acid cycle. J Clin Invest 93: 870-876

32. Crespin SR, Greenough WB, Steinberg D (1969) Stimulation of insulin secretion by infusion of free fatty acids. $J$ Clin Invest 48: 1934-1943

33. Campillo JE, Valdivia MM, Rodriguez E, Osorio C (1979) Effect of oleic and octanoic acids on glucose-induced insulin release in vitro. Diabete Metab 5: 183-187

34. Lee Y, Hirose H, Ohneda M, Johnson JH, McGarry JD, Unger RH (1994) $\beta$-Cell lipotoxicity in the pathogenesis of non-insulin-dependent diabetes mellitus of obese rats: impairment in adipocyte- $\beta$-cell relationships. Proc Natl Acad Sci 91: 10878-10882

35. Svedberg J, Björntorp P, Smith U, Lönnroth P (1992) Effect of free fatty acids on insulin receptor binding and tyrosine kinase activity in hepatocytes from lean and obese rats. Diabetes 41: 294-298

36. Williamson JR, Browning T, Sholz R (1969) Control mechanisms of gluconeogenesis and ketogenesis. 1. Effects of oleate on gluconeogenesis in perfused rat liver. $\mathrm{J}$ Biol Chem 224: 4607-4616

37. Foley J (1992) Rationale and application of fatty acid oxidation inhibitors in treatment of diabetes mellitus. Diabetes Care 15: 773-784 